\title{
UNDERSTANDING THE “HYBRID” MEDIA IN DESIGN EDUCATION
}

\author{
Barış ATİKER \\ *Beykent University, Faculty of Fine Arts and Design, Istanbul, Turkey \\ barisatiker@beykent.edu.tr
}

\begin{abstract}
The digital transformation of moving images in the last 30 years has resulted with revolutionary impact on art and design fields. The increasing use of digital technologies for creating design and artwork with moving images has united many disciplines such as graphic design, photography, painting, cinematography, animation, three-dimensional visualization and typography, so that the moving image is no longer pure. According to Manovich, the combination of different disciplines within moving image has created a "hybrid" media where the different image layers are interacting with each other and this interaction is not only in the slight transition between different image layers, but also the transition between the production techniques and conceptual representations of them. The shifting from real to hybrid images provides many opportunities for creative solutions, but then the designer becomes more dependent on digital technologies. However the "hybrid" media and visual language should keep evolving and transforming as a combination of different disciplines, so that the design education perspective should move from software-based education to the new visual aesthetics. Thereby the creative solutions offered by the software will turn into new challenges and design experiences. This paper aims to explore the understanding of "hybrid" media's visual language in design education through the frame of basic and new design principles.
\end{abstract}

Keywords: Hybrid media, Design education, Visual language, Design principles

\section{INTRODUCTION}

"The hybrid or the meeting of two media is a moment of truth and revelation from which new form is born" [11]

With the arise of personal computers and digital design technologies in the last quarter of $20^{\text {th }}$ century, the disciplines which described previously separate like cinematography, animation, graphic design, photography, typography and animation, have began to unite with the help of design software such as Adobe Photoshop, After Effects and Flash. According to Manovich, by the end of the decade, the "pure" moving-image became an exception and hybrid media became the norm. [10]

The combinations of different disciplines, whether they are visible or not, resulted in unexpectedly because they were also combinations of different characteristics of different media types. Because the content of a new medium is some other older medium, there is a sense in which the new medium is a hybrid in that it possesses some aspects of the older media, which forms its content but presents it in a new context and hence creates new effect. [8] According to Davies and Parrinder, these combinations can be called articulated media, because the tempo and the nature of each media is distinct - even they are networked. Visualisations end up as objects in the world. [2] Long before the digital revolution on image creation, McLuhan has already stated the crossing or hybridization of the media release great new forces and energy by fission (as in literate media) and fusion (as in electric media) [11] It's much more important to understand what will be the effects of using hybrid media in design education today. Because of many creative and artistic possibilities within the new media, we have to define the hybrid processes first. 
The revaluation of old media through the prism of new media, or the visioning of new media possibilities through the lens of old media, is a response to the phenomenon of convergence in technologies and media ownership. This convergence suggest the overlapping practices, dissolving of conceptual boundaries of potential meaning and the emergence of new hybrid practices. [3]

\section{GRAPHICS IN HYBRID MEDIA}

Everything we see on the screen has already become a product of hybrid media, from Hollywood movies to TV commercials, motion graphics, websites, animations created by professional or amateur designers and students. Manovich states that the new hybrid visual language of moving images has dominated the global visual culture today. [10]

First advantage of hybrid media is giving the possibility of a new stylized aesthetics, which is impossible by only live action footage or $3 \mathrm{~d}$ computer animations. That's why Manovich describes the result of hybridization process is not only the sum of previously existing parts but a new "species"- a new kind of visual aesthetics that did not exist previously. [10]

There are several techniques to embed one image into another. Rotoscoping and chroma keying are techniques commonly used to isolate objects from the footage. So these objects can be overlayed with different image layers to produce non-existing scenes before. In the movie "The 300 Spartans (2006)" all action sequences are filmed in studio for keying technologies and the digital landscapes embedded to the studio shots.

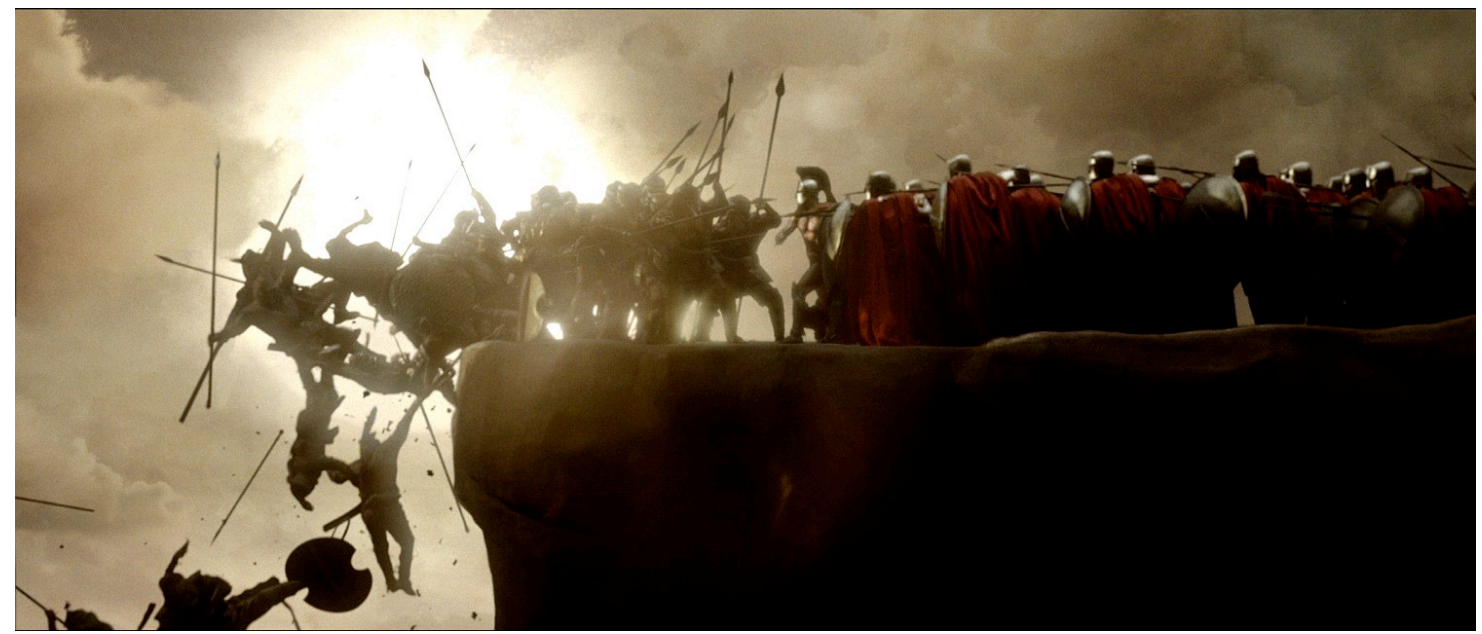

Figure 1. War scene from The 300 Spartans movie. Director: Zack Snyder. Warner Bros.

And second advantage of hybrid media is the designer's control ability on different image layers whether the visibility or different visual effects such as blur and transformations. This provides the designers endless creative design solutions.

The origin of the creativity in hybrid media comes from not only the remix of image layers but also their way of existence. Manovich calls this as a "hybrid revolution" where everything is in a "deep remixability" and what gets remixed is not only content from different media but also their fundamental techniques, working methods, and ways of representation and expression. He describes the combination of software environment, cinematography, animation, special effects, graphic design and typography forms a new "metamedium" and the work produced in this new metamedium can use all techniques, or any subset of these techniques, that were previously unique to these different media. [10] 
The digitalization of image has completely changed the way we create, produce and modify the media today. Manovich defines those changes as "extracting" the media from their particular physical medium of origin and turning them into algorithms. So none of these techniques will stay in their pure original state. He expresses the media techniques became "supercharged" and amplified; their range and application were extended; and their controls were made explicit, formalized, quantifiable and programmable. [10] So design processes is much powerful and effective than traditional design approaches.

\section{DIMENSIONS IN HYBRID MEDIA}

According to Manovich, although the particular aesthetic solutions vary from one video to the next and from one designer to another, they all share the same logic: the simultaneous appearance of multiple media within the same frame. [10] The dimensions of the images depend on the frame. Woolman defines the frame in film as both the image on the film and the dimensions of projected screen; the frame in video as the video monitor; and the frame in digital media as the rectangular bounding area that confines the sequence. [16]

Since the computers have capability to construct a three dimensional image design where objects appear to have volume, weight and mass when they are void of such attributes has the power to titillate the eye and the mind. That is what every designer wants to achieve, to make the audience look twice. [4] Embedding virtual images to real footage is a real challenge for the designer, where the total look will be artificial or seamless. That's why it's so common to use the real world references on the image itself, such as depth of field, motion blur, lens effects, where the goal is achieving the photorealist perfection. Manovich explains once that technique became available, designers gradually realized that it could be used as regardless of how realistic or abstract the overall visual style was as long as there was a suggestion of three dimensional space. [10]
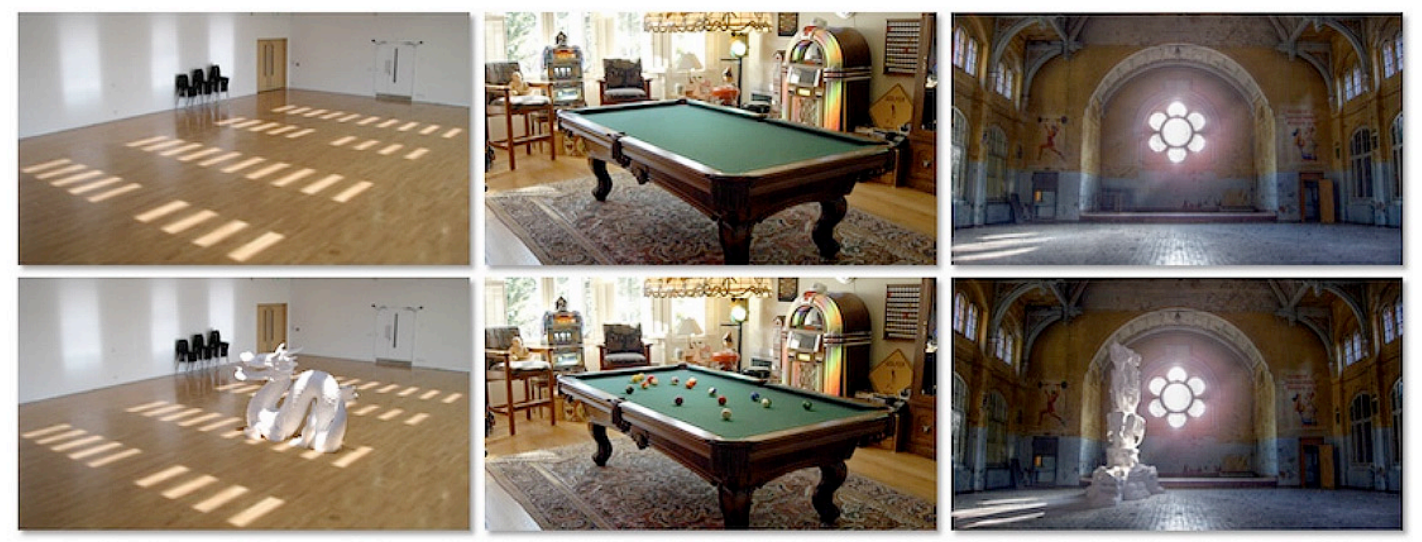

Figure 2. 3D Objects embedded in 2D photographs. Kevin Karsch, Varsha Hedau, David Forsyth, Derek Hoiem. SIGGRAPH Asia 2011.

Motion tracking softwares are capable of giving the exact coordinates of the space to embed three dimensional objects into the scene. So designer is no longer limited by two dimensional and physical borders of the frame, instead one can obtain necessary data from the moving image itself and use this data to embed virtual images directly to the scene; even in realtime.

Augmented Reality (AR) applications are a good example of this. Image projections on any three dimensional objects combines architecture, modelling, sound sync, motion graphics and games all at once. Azuma defines the Augmented Reality as users see the world around them with virtual objects superimposed upon or composited with the real world. Augmented reality applications combining the real and virtual worlds, interactive in real time and registered to 
three dimensional objects. So Augmented Reality enhances a user's perception of and interaction with the real world. [1]

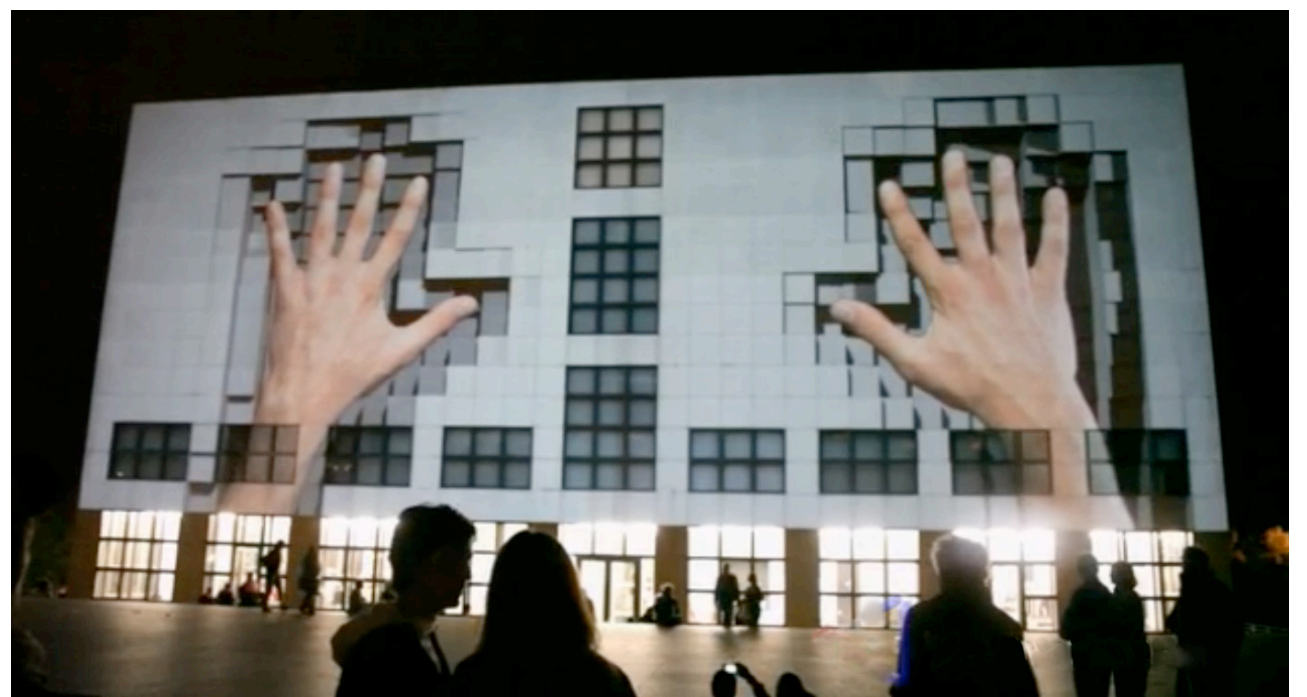

Figure 3. "555 Kubic" by UrbanScreen.Projection Mapping. Hamburg,Germany.2009.

Within the new dimensions of the frame, hybrid media always keeps changing and effect the frame as a whole. Manovich points out the transformations in the frame such as transformation of visual elements, transparency of objects, textures of the images etc. and if something stays same for a while, that's an exception rather than the norm. [10]

\section{TYPOGRAPHY IN HYBRID MEDIA}

The word typography is already a hybrid of type and graphics. Considering that multimedia is a hybrid of various conventional media such as cinematography, animation, graphic design and typography, we need to acknowledge that typography is more or less a hybrid of text and image. [5]

Although the hybridization of type has started so long ago, the process become much more accelerated with the help of technological tools. In the 1970's, a digital signal began to supplant the photographic negative as the means of reproducing the typographic forms. In the electronic environment of contemporary type design, scanned alphabets can ben endlessly manipulated by the type designer, serving either as models for accurate reproduction or as skeletons for new or hybrid designs. [9] Now in the digital era, there are limitless opportunities to manipulate and embed type into the image whether it's moving or not. Hillner suggests that from a design perspective a typographic message is composed rather than written. The arrangement of words, sentences and blocks lends the text an image-like quality. Due to it's metalinguistic architectural characteristics, typography is scanned as well as read.[5]

Samara evaluates the relationship between type, word and image as an interaction between them happens as a result of their similar abstract pictorial qualities. Both images and type share the same attributes such as lighting, volume, contours, open and closed spaces and arrangements. She emphasizes the task is to find where the specific attributes of both come together. [13] The visual relationship between type and image is different in hybrid media, because of the continuous movement and transformation of the image. Motion typography is as old as the cinema, but the demand in juxtaposing type with the image is much more challenging today. For example, embedding three dimensional typography into moving images needs more visual attributes like shadows, depth of field, perspective and motion rather than just overlaying layers. 


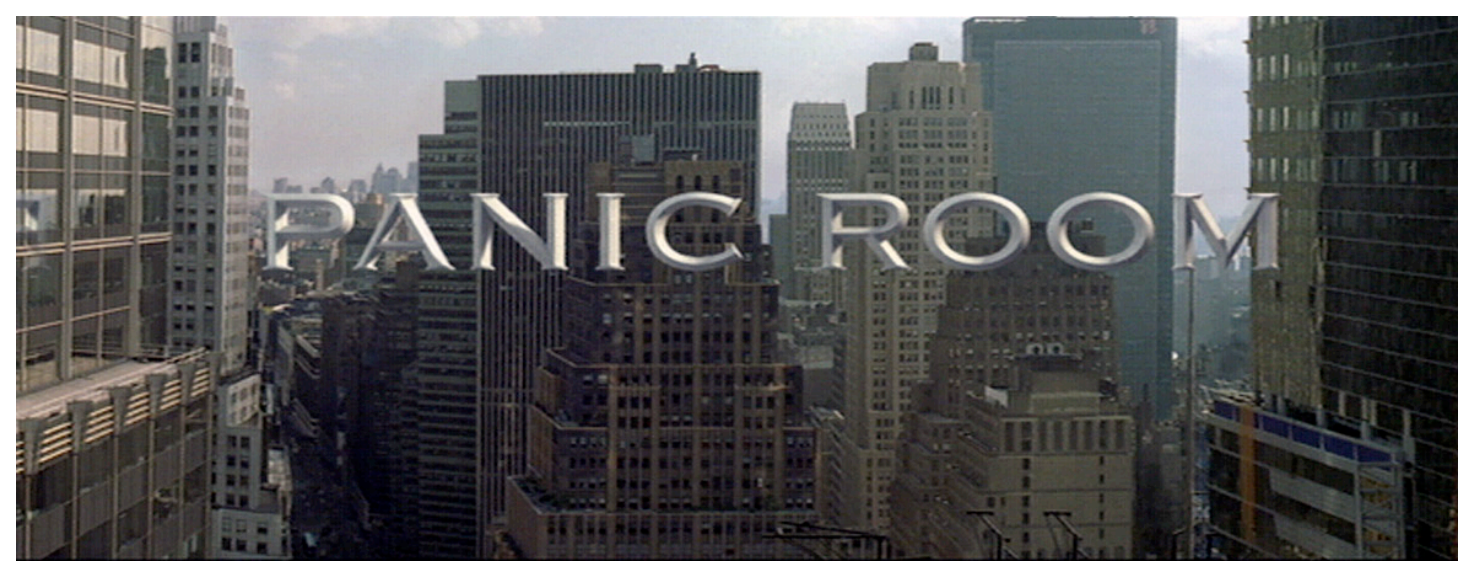

Figure 4 3D Titles for "Panic Room" movie. Director David Fincher.Columbia Pictures.2002.

Motion typography is such a powerful tool to express the unprecedented kinds of visual aesthetics in time based media. Hillner explores the aesthetics can only be understood in relation to perception and we know rather little about the innovative value of multimedia typography beyond the processes of production. He also raises the question what exactly causes the viewer's mode of perception to change and in what way are people's senses being altered within hybrid media. [5] Hillner explains that if transitions between image and text patterns are repeated systematically, virtual typography stimulates the viewer's mind due to its transitional characteristics as well as the viewer's expectation of recurring patterns. While one word takes shape, is read and reflected upon, another one emerges so that the momentum is sustained. The intellectual reflection that follows the cognitive phase is accompanied by the next phase of aesthetic stimulation.[5]

\section{INTERFACES IN HYBRID MEDIA}

As long as the mobile devices begin to rule our communication world, Johnson states that the interfaces define our perceptions of the space we inhabit, as well as the type of interaction with other people with whom we might connect. [6] According to Silva, with the use of mobile interfaces such as cell phones, netbooks and ipads, the border between physical and digital spaces are blurred. Especially the social networks are brought into physical spaces with the mobile interfaces. This is hybrid space which are created by constant movement of users who carry portable devices continuously connected to the Internet and to other users. [14]

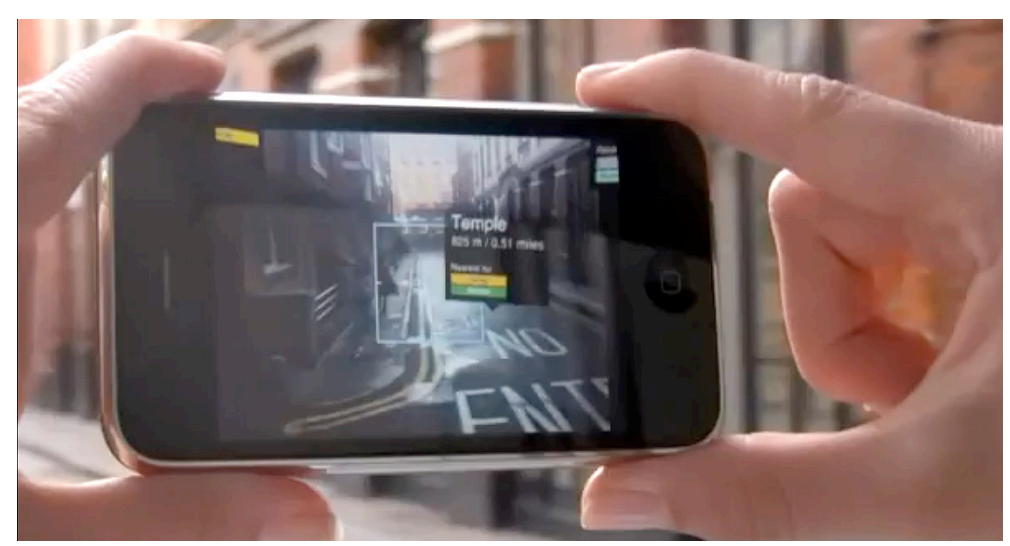

Figure 5. Nearest Tube Augmented Reality Application Interface for IPhone.

The continuity is a priority concept in hybrid media because all the possible forms - visual, 
temporal, spatial, interactive - are similarly represented as sets of variables that can change continuously. Manovich emphasizes this new logic of form is deeply encoded in the interfaces of software packages and the tools they provide. Those interfaces quickly led to a new aesthetics: the continuous transformations of all image elements and often the image as a whole. [10]

The understanding of interface are also changing in hybrid media. Rather than controling the graphical images with buttons such as play rewind and pause, O'Neill states that we should also see hybrid multimedia applications in their own right. Just as the logic of the printed page still dominates how we lay out our interactive screens, the logic of film still dominates how we deal with moving images at the interface. Shots, pace, angle and narrative structure have never been more important to understand the moving image as they are in interactive media today. [12]

Manovich explains that although a particular software application does not directly prescribe to its users what they can and cannot do, the structure of the interface strongly influences the designer's thinking. [10]

\section{SOUND IN HYBRID MEDIA}

Sound is a very basic design tool when considered in motion graphics. According to Strizver the incorporation of sound with motion graphics gives it another dimension, so to speak. The addition of music, voice and the spoken word, as well as other sound effects, adds a very powerful, emotional element that can go a long way toward the setting of the mood, conveying a message, as well as drawing attention to and emphasizing or reinforcing a particular frame or segment. [15]

Sound is no longer a supporting tool to emphasize the meaning and expression of the images. Instead, sound is directly used as the source for creating the visuals. With the help of design softwares the data such as frequency or loops which obtained from the sound can be transformed into highly aesthetic visual solutions and now the roles between sound and images have changed dramatically. One of the most common examples of software for sound visualization is the one used in media players. But sound in hybrid media is much more than what we see in media players. Lexmann explains the relationship of sound with visuals is based on a temporal and spatial concept while the "film space" enforces the impression of a space outside the projection scope in which the spectators seemingly find themselves, nowadays it may be termed the "visual space" taking into consideration the broader context of the audiovisual expression. [7]

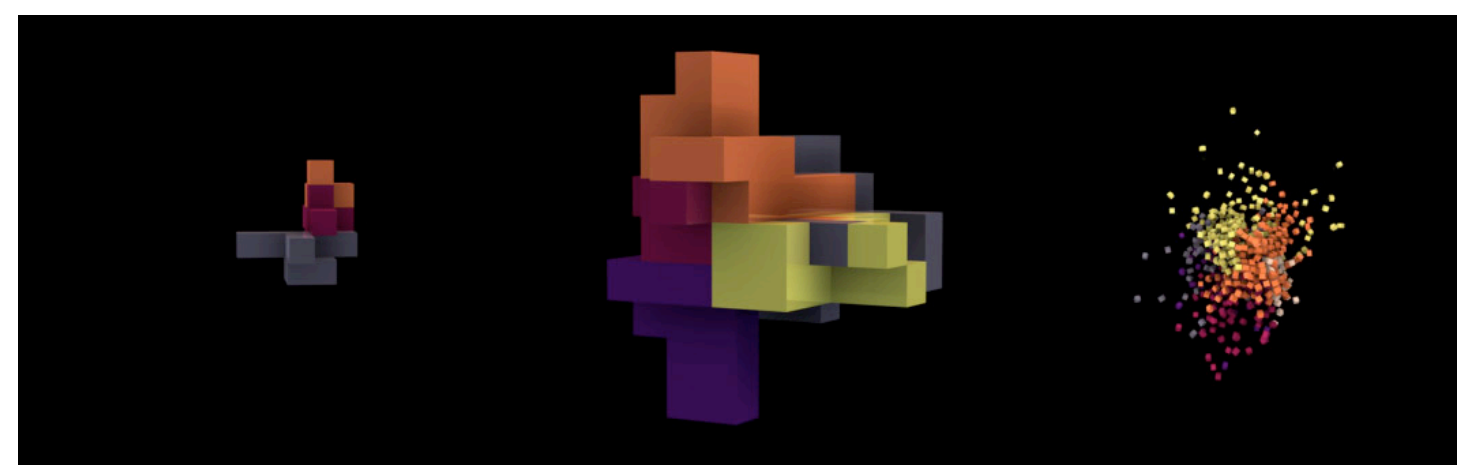

Figure 6. Piano Cubes by Max-Heinrich Müller. Music Visualization of Frederic Chopin's Ballade No.1 


\section{CONCLUSION}

Hybrid media changes the way we look at the image and design. Within all elements forming the image, all constants are substituted by continuously changing variables controlled by the designer. Manovich expresses the idea of today's visual culture can be called the "continuity turn" [10]

So it's better to arise the question of what will this continuity bring to design processes. Working with interdisciplinary fields, the designer is face to face with a challenge for discovering the unexplored potential of new aesthetics. The images designer creates are as limitless as one's imagination. But it takes talent and genius to extract the creative ideas from the possibilities of software-using skills.

According to Manovich the hybrid image will skillfully play on the visual and semantic differences between live-action footage, drawings, photographs with animated filters on top of them, and other media, these differences do not create juxtaposition or stylistic montage. Instead, various media seem to peacefully coexist, occupying the same space. Those images offer us distinct and original visions of our world in the stage of continuous transformation and metamorphosis: visions that are fully appropriate for our time of rapid social, technological and cultural change. [10]

Today hybrid media requires the design education to be in a broader perspective. The image, type, motion, time, sound and interaction should be revaluated with traditional design principles which are still ruling the way we design. Therefore we need to prepare for new vocabularies which will arise from the new tools, processes, dimensions and shortcomings of digital production.

As IcoGrada (International Council of Graphic Design Associations) has declared in 2000, the design education should focus on critical mentality combined with tools to communicate.It should nurture a self-reflective attitude and ability. The new program should foster strategies and methods for communication and collaboration.

Davies and Parrinder call attention to avoid fetishising this technology. They hope the future designer will hi-jack these technologies to a different and more reciprocal end; that's engaging with the nature and tempo of technology but with human nature and tempo also articulated. [2]

\section{REFERENCES}

[1] Azuma, R.(1997). "A Survey of Augmented Reality", Presence: Teleoperators and Virtual Environments 6 (4): 355-358.

[2] Davies, C. , Parrinder, M. (2009). Limited Language: Rewriting Design: Responding to a Feedback Culture. Basel: Birkhäuser Architecture.

[3] Dewdney, A.(2006). New Media Handbook (Media Practice). New York:Routledge.

[4] Heller, S.(2010). Pop: How Graphic Design Shapes Popular Culture, New York: Allworth Press.

[5] Hillner, M.(2009). Basics Typography: Virtual Typography. West Sussex: Ava Publishing SA.

[6] Johnson, S.(1997). Interface Culture: How New Technology Transforms The Way We Create and Communicate. San Francisco: Harper's Edge.

[7] Lexmann, J.(2008). Audiovisual Media and Music Culture. New York: Peter Lang GmbH.

[8] Logan, R.(2010). Understanding New Media: Extending Marshall Mc Luhan. New York: Peter Lang Publishing.

[9] Lupton, E.(1996). Mixing Messages: Graphic Design in Contemporary Culture, New

York: Princeton Architectural Press. 
[10] Manovich, L.(1997). “Understanding Hybrid Media” In: Betti-Sue Hertz (ed.), Animated Paintings. San Diego: San Diego Museum of Art.

[11] McLuhan, M.(1964). Understanding Media: The Extensions of Man. New York: McGraw Hill.

[12] O’Neill, S.(2008). Interactive Media: The Semiotics of Embodied Interaction. New York: Springer .

[13] Samara, T.(2006). Typography Workbook: A Real World Guide to Using Type in Graphic Design. Minneapolis: Rockport Publishers.

[14] Silva, A..(2006) "From Cyber to Hybrid: Mobile Technologies as Interfaces of Hybrid Spaces" Available at http://tvdigital.files.wordpress.com/2008/09/mobile-2006-adrianasilva.pdf [10 November 2011].

[15] Strizver, I.(2010). Type Rules!: The Designer's Guide to Professional Typography. New Jersey: Wiley.

[16] Woolman, M.(2000). Moving Type: Designing For Time and Space, Amsterdam: BIS Publishers. 